\title{
The approach to the asset management strategy choice in an electric grid company
}

\author{
I. Volkova ${ }^{1} \&$ E. Kornienko ${ }^{2}$ \\ ${ }^{I}$ National Research University, Higher School of Economics, Russia \\ ${ }^{2} J S C$ "Russian Grids", Russia
}

\begin{abstract}
Nowadays, the formation and development of an asset management system of "Russian Grids" is one of the key processes and priorities of the company, covering all levels of management. On the one hand, the relevance of finding an optimal asset management strategy is caused by a necessity to synchronize the strategies of different business levels with the company's strategy and to transmit the relationships between the strategies into the key performance indicators of business processes. On the other hand, all the subsidiaries of "Russian Grids" are at different levels of development, and the same goals could not be achieved by all companies at the same time. This paper considers one of the possible approaches to searching an optimal asset management strategy for subsidiaries under the general direction of unified asset management strategy development and the corporate strategy. The asset management strategy choice depends on the level of its maturity and efficiency of the company with a necessity to synchronize the strategies of different business levels and to decompose relationships between these strategies through corresponding key performance indicators.
\end{abstract}

Keywords: asset management strategy, corporate strategy, key performance indicators, reliability of power supply, JSC "Russian Grids".

\section{Introduction: the process of the corporate strategy formation}

Modern management theory considers the existence of company strategies on corporate, business, functional and operational levels of governance. The corporate level implies the description of an overall system of achieving 
the desired results and its position on the market. The strategies of other levels represent and deeper specify a company strategy. They imply full conformity with the strategic goals of the company and the internal consistency on vertical and horizontal levels of the development.

The business level details approaches to solving problems in achieving the strategic goals of the company. It creates a set of techniques for managing business processes of the company and provides the description of business processes and set of measures to adapt to changing conditions in the industry and the economy as a whole.

The functional level implies an action plan for each functional subdivision of the company, subsidiary or affiliate (production, asset management, R\&D, sales, financial activities, personnel policy, etc.)

The formation of a company operations strategy is the fourth and the most detailed level of strategy development. It defines the format, action plan and governance principles for basic structural units within the functional subdivisions.

Thus corporate strategy in itself is a complex of strategies created on different management levels on behalf of the company. The reconciliation of strategies goals along the corporate structure hierarchy is needed to prevent disagreements and discrepancies in vision of subdivisions activity vectors. A corporate strategy is further detailed in every next level and determines the specific work of each affiliate, subdivision, department and employee, as well as their goals and key performance indicators.

The formation of KPI system for company activities and KPI blocks for each governance level from top to bottom is an effective way to detail a strategy. Herewith raises a need to determine specific parameters that affect the formation of indicators and KPI blocks, as well as their compliance with each of the strategy levels. Table 1 shows the map of KPI compliance with the different levels of the strategy formation.

\section{The approach to choosing the asset management strategy}

\subsection{Asset management is a key process to reaching company efficiency}

Asset management is one of the strategic directions of the infrastructure companies, which operate in a natural monopoly and price regulation environment and operate for a large park of assets involved in the primary production activities and spread over a wide area of one or more countries. And the priority is to form and develop a precise asset management system as a tool which allows us to find the optimal balance between production efficiency, technical risks and their costs considering the strategic goals of the company and the interests of stakeholders.

In the process of developing the strategy companies should focus on the requirements to the results of its operations from external and internal stakeholders: consumers, state, regulators, companies operating in the same sector, shareholders, managers and employees of the company. The objectives 
Table 1: $\quad$ The map of KPI blocks compliance with the different levels of an electric grid holding strategy development.

\begin{tabular}{|c|c|}
\hline $\begin{array}{c}\text { Strategy } \\
\text { development } \\
\text { level }\end{array}$ & KPI blocks (benchmarking) \\
\hline
\end{tabular}

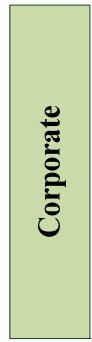

Control of company's strategic goals

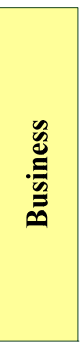
realization

Increase efficiency and reduce costs in the company by activity

Increase efficiency and reduce costs in the whole company

Estimation of financial and production KPI

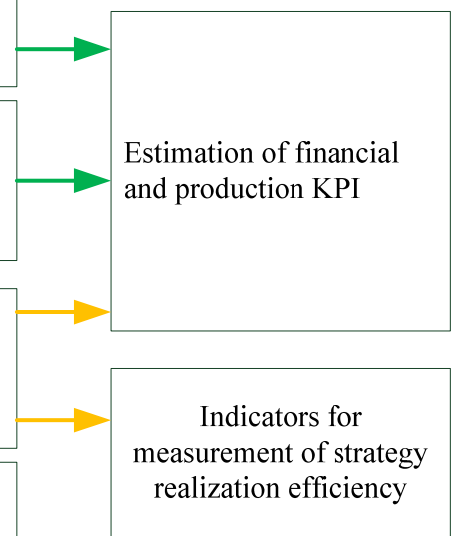

Integral assessment of increasing efficiency and cost reduction in the company in context of the key processes

Increase company efficiency and reduce costs in the context of the key processes by departments of:

- Maintenance and repair

- Investment management and constructions

- Electricity transportation and accounting

- Planning grid development

- Operational and technological control

- Logistics and purchasing

- Taxes and accounting

- Finance and economy

Specification of company efficiency and cost reduction in in the context of the key processes
Indicators for measuring financial efficiency in terms of:

- Revenue

- Maintenance costs

- Investment costs

- Financial results

- Other indicators

Indicators for measuring production efficiency in terms of:

- Reliability

- Electricity losses

- Specific sustained outages

- Amount of outages

- Quality of service

- Technical risks

- Other indicators 
and requirements of stakeholders are often conflicting, so it is necessary to balance the interests of all stakeholders.

Usually there are such conflicting goals, as improving production efficiency and reduce operating and investment costs. And any financial, economic, technical, technological and organizational solutions entail changes in the related areas.

The asset management system can help companies to prioritize and determine the sequence of solving problems at various levels of governance. Thus it is necessary to transmit company strategy and the key performance indicators of business across the whole organizational vertical and all processes.

The main objectives of the asset management system are:

- increase technical and technological efficiency;

- increase efficiency of operating and investment costs of production;

- increase the life circle of the equipment;

- decrease technical risks of the equipment failure ;

- decrease downtime;

- increase productivity, etc. [1,2].

The objectives of solving asset management problems under common strategic goals in fixed period may not be the same for all subsidiaries (business units) of the company, as they are at different levels of technological and economic development, in various financial conditions, operate in different regions or countries with various climate, own the equipment in the various technical conditions, degree of deterioration and etc.

Thus, the level of technical, technological, economic and financial development of the business unit depends on the maturity level of the subsidiary as a whole. The maturity level and the business efficiency determines the level of development of approaches to the asset management strategy choice, the asset management techniques and methods [2]. Figure 1 shows the sequence of formation of the corporate strategy and the asset management strategy (in the electricity grid company for example).

\subsection{The methodology of choice the asset management strategy}

There are different approaches to divide asset management strategies in the international practice. One of them suggests tracing the evolution of the asset management strategies depending on technical conditions and importance (risk of failure or downtime) of equipment: corrective strategy, time based strategy, condition based strategy, reliability centered strategy [3]. Figure 2 gives an overview of this classification and shows the evolution of asset management strategies in two coordinate systems - coordinate system of governing decision characteristics and coordinate system of consideration assets characteristics in asset management strategy choice.

Technological, economic and organizational efficiency of asset management increases with the efficiency of decision making in certain situations, as part of the asset management strategy, and a rate of decision making, which is characterized by the decision point (after the accident, before the accident, or in a real time). 
Sequence of the development of corporate and the asset management strategy
Sequence of KPI formation as a tool for implementing and monitoring the implementation of corporate strategy and the asset management strategy

\begin{tabular}{|c|c|c|}
\hline \multicolumn{2}{|c|}{$\begin{array}{c}\text { External and internal stakeholders' } \\
\text { requirements }\end{array}$} & Formalized stakeholders' requirements \\
\hline \multicolumn{2}{|c|}{$\downarrow$} & $\boldsymbol{\nabla}$ \\
\hline \multicolumn{2}{|c|}{ Corporate strategy } & KPI of corporate strategy realization \\
\hline \multicolumn{2}{|c|}{$\downarrow$} & $\hat{\nabla}$ \\
\hline \multicolumn{2}{|c|}{ The unified asset management strategy } & $\begin{array}{c}\text { KPI of the unified asset management } \\
\text { strategy realization }\end{array}$ \\
\hline \multicolumn{2}{|c|}{$\downarrow$} & $\theta$ \\
\hline \multicolumn{2}{|c|}{$\begin{array}{l}\text { The asset management strategy } \\
\text { for the business unit: } \\
\text { - Corrective AM Strategy } \\
\text { - Time Based AM Strategy } \\
\text { - Condition Based AM Strategy } \\
\text { - Reliability Centered AM Strategy }\end{array}$} & $\begin{array}{l}\text { Efficiency estimation of the asset } \\
\text { management strategy } \\
\text { for the business unit }\end{array}$ \\
\hline \multicolumn{2}{|c|}{$\downarrow$} & $\boldsymbol{\nabla}$ \\
\hline \multicolumn{2}{|c|}{$\begin{array}{c}\text { The system asset management plan } \\
\text { (in functional and operating levels of } \\
\text { governance) }\end{array}$} & $\begin{array}{l}\text { Integral assessment of the AM strategy } \\
\text { effectiveness of the key processes }\end{array}$ \\
\hline & $\hat{\nabla}$ \\
\hline Operating assets & New assets & $\begin{array}{l}\text { Detailing the effectiveness of the key processes } \\
\text { (for the electric grid company): } \\
\text { - Maintenance and repair }\end{array}$ \\
\hline$\downarrow$ & $\downarrow$ & - Investment management and constructions \\
\hline $\begin{array}{l}\quad \text { Strategy of: } \\
\text { - Maintenance } \\
\text { - Repairs } \\
\text { - Replacements } \\
\text { - Assets' lifecycle } \\
\text { management }\end{array}$ & $\begin{array}{l}\quad \text { Strategy of: } \\
\text { - Project management } \\
\text { - Assets' lifecycle } \\
\text { management }\end{array}$ & $\begin{array}{l}\text { - Electricity transportation and accounting } \\
\text { - Planning grid development } \\
\text { - Operational and technological control } \\
\text { - Logistics and purchasing } \\
\text { - Taxes and accounting } \\
\text { - Finance and economy }\end{array}$ \\
\hline $\mathbf{A}$ & $\mathbf{A}$ & $\mathbf{4}$ \\
\hline \multicolumn{2}{|c|}{$\begin{array}{l}\qquad \begin{array}{l}\text { AM methods and techniques } \\
\text { at governing levels of: }\end{array} \\
\quad \text { - Database of assets, their condition, consumers, grid } \\
\text { topology, etc. } \\
\text { - Regulatory and methodological framework } \\
\text { (methods, algorithms, processes, regulations, KPIs, } \\
\text { etc.) } \\
\text { - Technologies, techniques, IT infrastructure and IT } \\
\text { solutions } \\
\text { - Organization of the AM processes }\end{array}$} & $\begin{array}{l}\text { - Regulatory and methodological base for the KPI } \\
\text { calculation } \\
\text { - Data base for the KPI calculation } \\
\text { - IT infrastructure for the KPI calculation } \\
\text { - Organization of the accounting, monitoring KPI and } \\
\text { making governing decisions process }\end{array}$ \\
\hline
\end{tabular}

Figure 1: Sequence of the development of the corporate and the asset management strategy.

During the implementation of a certain asset management strategy, achieving goals and positive results subsidiary moves to a qualitative new efficiency and maturity level. Thus, the company can set the new goals and make the search for the new ways of solving problems and expansion of business, different from those used at an earlier development level. This transition determines the new asset management strategy. 
The approach to the asset management strategy choice in a subsidiary of an electric grid company in the frame of the unified asset management strategy and corporate strategy can be based on the efficiency and maturity level of the business unit. At the same time it is the necessary to harmonize and unify asset management methodology and the description of the processes at the corporate strategy level. Figure 3 presents the process of selecting the asset management strategy for a business unit

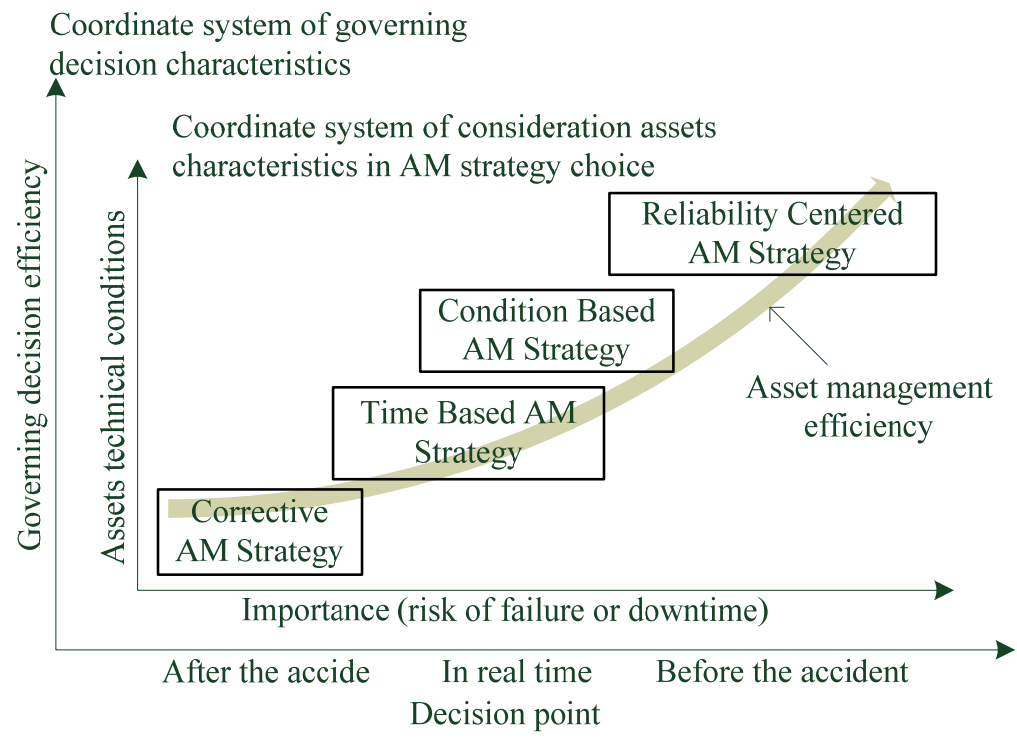

Figure 2: The evolution of the asset management strategies.

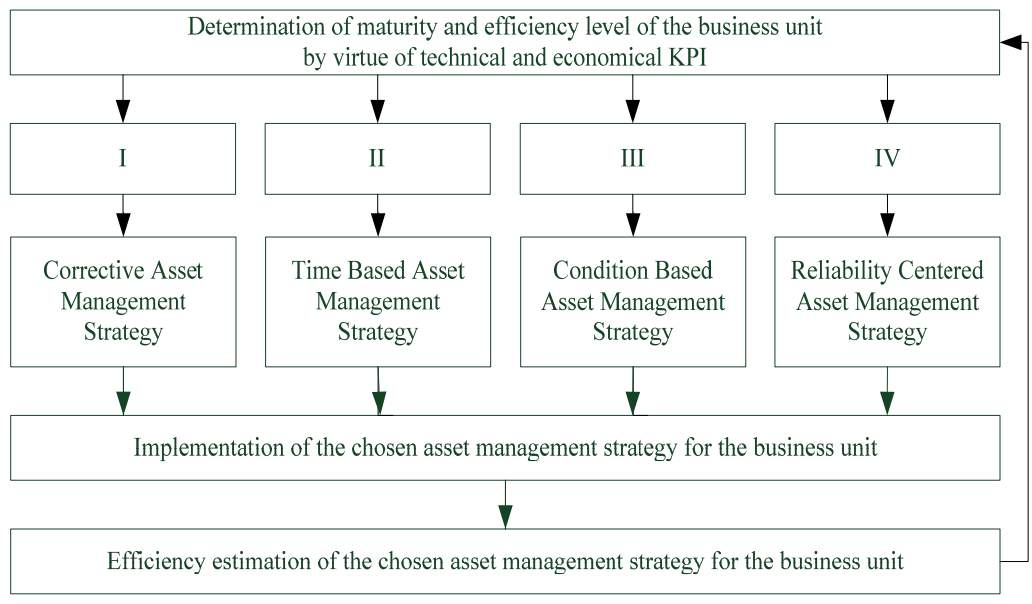

Figure 3: The process of the selecting the asset management strategy for the business unit. 
The formation of the KPI system and KPI targets on each maturity level of a business unit, as well as asset management strategy is a tool that allows a subsidiary to track, monitor and control the business processes and plan the development [4].

The asset management strategy can be justified through the integration key performance indicators of the unified asset management strategy into the proposed map of the company KPI (fig. 1). The efficiency map of the unified asset management strategy based on the matching different KPI block of the different levels of the corporate strategy (Table 2).

The arrows on the map show the relationship of indicators' blocks and different strategy levels among themselves. Relationships imply a single nature and hierarchical level of the strategy where key performance indicators appear. The arrows indicate specific level of the strategy. And particular key performance indicators cover those levels of strategy.

The general analysis of Table 2 gives the opportunity to justify the choice of the asset management strategy through the establishment of the relationships and hierarchy between blocks of the corporate strategy KPI and the asset management strategy KPI.

A logical transition from one strategy to another is caused by fully achieved targets (Table 2) at each stage of development of the asset management system, fig. 1. Business units release funds and can more freely make management decisions regarding the development of the businesses, including the transition to a new asset management strategy. This transition is possible with a clear built system of evaluation of the corporate strategy KPI and the asset management strategy KPI (fig. 1).

\section{The choice of the asset management strategy for the electric grid company JSC "Russian Grids"}

This paper represents an approach to the choice of the asset management strategy for subsidiaries of the electric grid company "Russian Grids". The analysis and conclusions are based on the open source materials. The approach assumes the necessity to synchronize different strategy levels and to decompose the relationships of them through the corresponding key performance indicators.

The mission of one of the world's largest electric grid companies "Russian Grids" is to lead in developing the management system of the transmission and distribution grid sector, providing reliable and high-quality electric power supply satisfying the growing demand of the Russian economy and social sector at service prices affordable for customers [5]. "Russian Grids" holding manages fifteen subsidiaries with 79 branches, which own a large number of assets. Nowadays, the formation and development of an asset management system of "Russian Grids" is one of the key processes and priorities of the company, covering all the levels of the strategy. 
68 Energy Production and Management in the 21st Century, Vol. 1

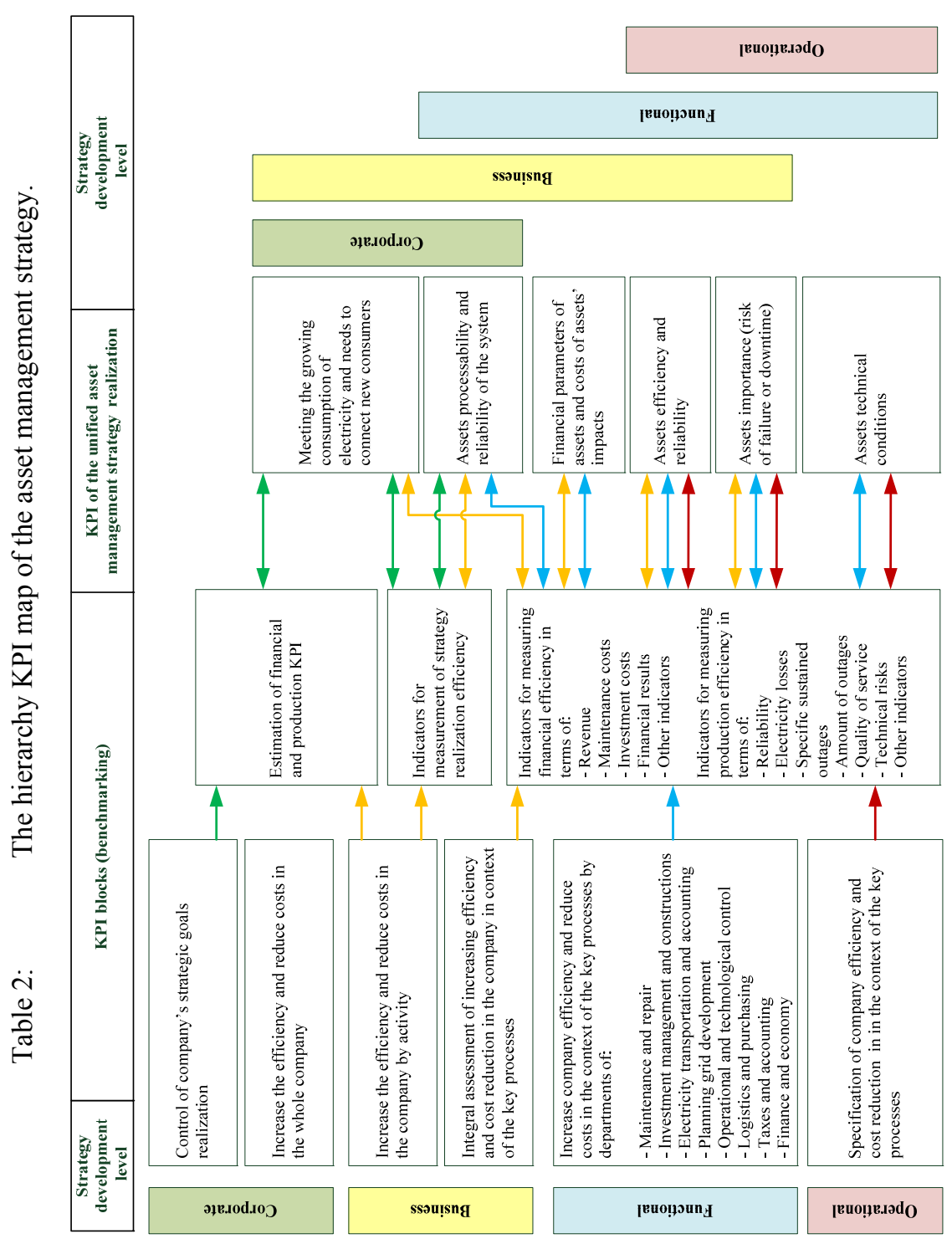


The asset management system is a tool to improve the efficiency and to solve problems of maximizing reliability provided to limit the costs of repairs, maintenance and replacement of equipment or minimize the expenditure required for inclusion in the tariff, to achieve the standard level of reliability. The main objectives of the company, as part of a project of production and development the asset management system to 2017 :

- ensuring regulatory standard reliability level of power supply, which becomes especially important in the conditions of freezing tariff growth in 2014;

- decreasing of electricity losses by $5 \%$ compared with 2012 ;

- decreasing of specific sustained outages by $5-10 \%$;

- decreasing of maintenance costs at $15 \%$;

- decreasing of equipment investment costs by $10-15 \%$;

- centralization of governing functions in the formation of the investment and maintenance programs;

- regular assessment, analysis and control of production efficiency, distribution of material resources to maintain regulatory level of reliability.

Currently, there are a lot of projects which aim is to solve individual asset management issues in the subsidiaries of "Russian Grids". A number of processes that provide control of assets efficiency is not unified and not formalized. Decomposition of KPI through the strategy levels of business units is carried out by benchmarking system and is not a subject of this paper. There is a question of selection asset management strategy of each individual business unit in the context of the heterogeneity of processes, methodologies, level of IT infrastructure development, and therefore different maturity and efficiency levels of subsidiaries.

KPI blocks for asset management system estimation (Table 3) are designed on the proposed approach, the map of the key performance indicators of the asset management strategy (Table 2) and the strategy of Russian electric grid development [5].

Current KPI are stated or each subsidiary, then the level of efficiency of the asset management process is estimated. It based on characteristics of methodology, regulatory documents, properties of IT systems and infrastructure. Thus the current workable asset management strategy is determined. Achieving target KPI of the asset management processes (Table 3) and current efficiency level will determine the necessity to move to a new asset management strategy of the subsidiary.

The calculations and analysis of the effectiveness of asset management processes allows us to conclude that at present the majority of subsidiaries of "Russian Grids" implement a corrective asset management strategy. Three subsidiaries JSC "FGC UES", "Tyumenenergo" and "Yantarenergo" are implementing the time based asset management strategy and have the potential to transmit to the condition based strategy providing an effective implementation of the adopted strategy. Two more subsidiaries of "Russian Grids" "IDGC of Center" and "Moscow United Electric Grid" are at the maturity level that can allow them to start implementation of the condition based strategy. 


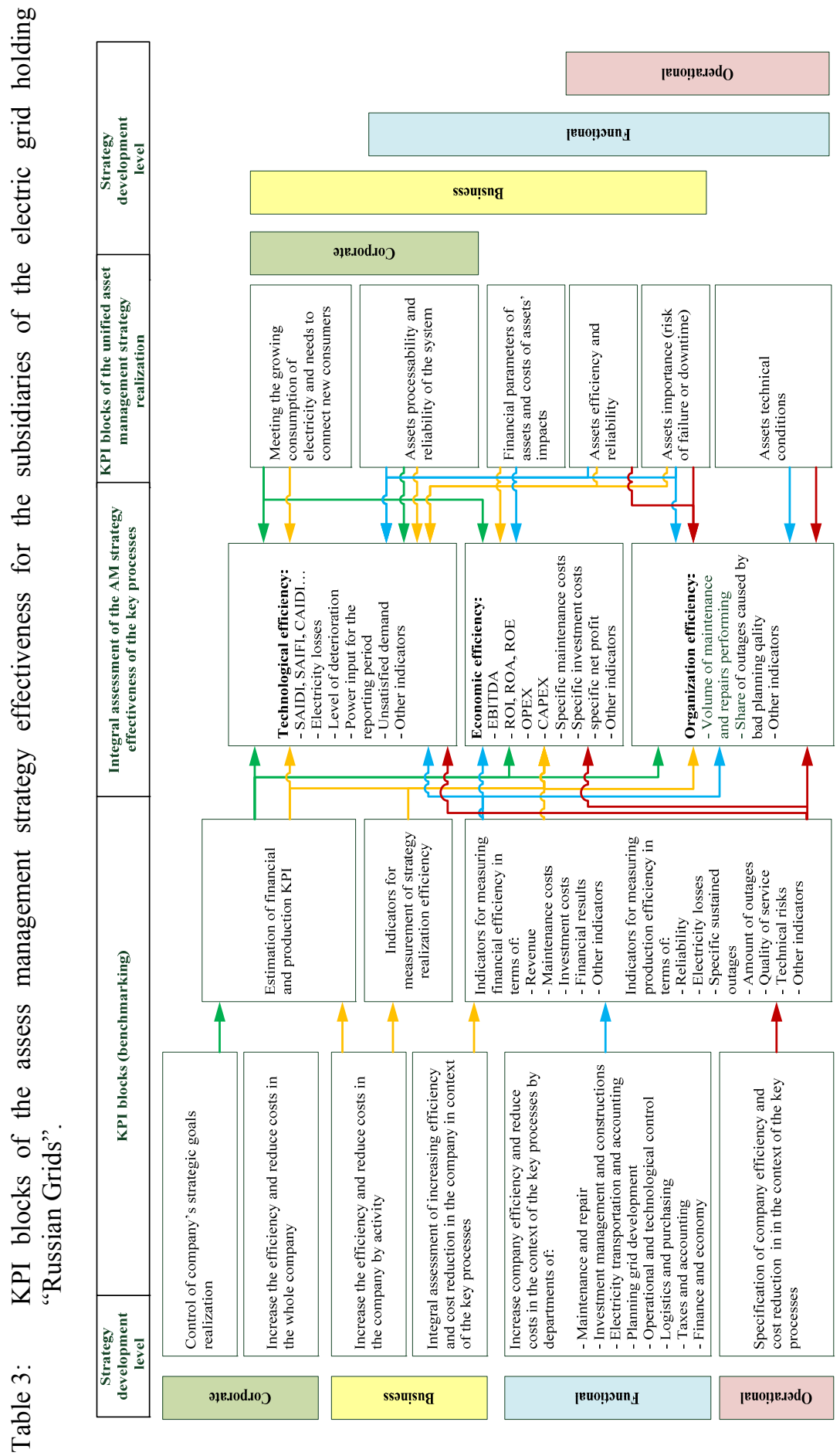




\section{Conclusions}

The process of choosing the asset management strategy for subsidiaries based on evaluation of business efficiency allows the company to monitor the development of business units and the company as a whole, as well as to avoid mistakes of total unification and choosing unified quantified objectives (KPI) in terms of diversity of internal and external factors affecting the business units production peculiarities. In general, the logical evolution of the asset management system and strategy of business units in the frame of the unified asset management strategy and the corporate strategy ensures the transition from the rational using of limited financial resources and their release to the development of technological systems, to managing complicated structural system highly technically and organizationally developed on the basis of the principles of assessment, control and analyzing risks, system conditions, selfregulation and self-healing.

\section{References}

[1] Ben-Daya, M., Duffuaa, S.O., Raouf, A., Knezevic, J., Ait-Kadi, D., Handbook of Maintenance Management and Engineering, Springer Dordrecht Heidelberg London New York, 2009

[2] Volkova, I., Efficient asset management in an electric grid company: theory and methodology, St. Petersburg Polytechnical University, 2008

[3] Schneider, J., Gaul, A., Neumann, C., Asset management techniques, 15th PSCC, Liege, August 2005

[4] Asset Management - an anatomy, The Institute of Asset Management, Issue 1.1, February 2012

[5] JSC "Russian Grids", http://rugrids.ru/eng/about/Mission-and-strategy/ 